\section{Effects of intralist activity on free-recall performance*}

\author{
DAVID S. GORFEIN $\dagger$ \\ New College, Sarasota, Fla. 33578
}

Performance in a free-recall paradigm was studied under five conditions of intralist activity. The activities were designed in such manner as to vary in their likelihood of blocking either rehearsal of the item, hooking contiguous items together, or both processes. The data support an explanation of free recall in terms of both of these processes being active with the major determinant of recall being the recirculation or rehearsal of the to-be-remembered item.

Glanzer \& Meinzer (1967) have examined the effect of intralist activity on the serial position curve of single-trial free recall. Particularly notable in their data was the decrement in primacy and middle portions of the curve produced by having $S$ continuously repeat an item during the presentation intervals. They suggest that the item repetition prevents effective rehearsal in free recall. In the present study an attempt is made to extend the studies of Glanzer and Meinzer with particular reference to the question of how much of a decrement is produced by item repetition as contrasted with other possible intralist activity. Specifically, in the present study we introduce an information-processing (IP) task as the inter-item activity. Two IP tasks differing in their demands were selected and paced in a comparable manner to the repetition condition. In effect, the low IP task required a single decision by the $S$ for each IP item and the high IP task required two decisions per item. In addition, in order to study the effects of the pacing variable, another group was run with the high IP task but with the task unpaced ( $\mathrm{S}$ was instructed to work as rapidly as possible). Since Glanzer and Meinzer had shown their effect to be localized outside the recency portion of the curve, it was decided that we would obtain maximal information from each trial if we manipulated Ss' postpresentation activity so as to minimize recency effects. We, therefore, following Glanzer \& Cunitz (1966) and Postman \& Phillips (1965),

* A number of the author's students participated significantly in the course of this study. I would therefore like to acknowledge the help of: Miss Kay Scheuerer and Mr. Donald Heth in data collection, and Mr. Christophe Arbak and Mr. Craig Evinger in data analysis. Professor Harry Crouch of the New College Physics Department programmed the statistical analyses for the computer and I am indebted to him.

$\div$ The author is particularly indebted to his colleague Mr. Raymond Bennett for critical discussion and advice throughout this study and in the preparation of this manuscript. delayed recall with a rehearsal-preventing task.

\section{METHOD}

Twelve Ss were assigned to each of five experimental conditions (standard free recall, repetition condition, paced low IP, paced high IP, and unpaced high IP).

Sixty undergraduate volunteers served as Ss and were assigned to conditions at random with the restriction that no condition have $\mathrm{N}+1$ Ss before every condition had had N Ss. All Ss were tested individually. All, excepting the standard free-recall group, were instructed that this was a study of their ability to do two tasks simultaneously and that their scores depended on doing both well. The free-recall task involved remembering 20-item lists of Thorndike-Lorge (1944) A and AA words selected so as to minimize intralist associations. Items were presented with a Kodak Carousel projector at a 4-sec rate. Each S saw 10 lists whose order was assigned using a balanced Latin square for the first $10 \mathrm{Ss}$ in a condition and with two of the rows in the Latin square repeated for the other two Ss in each condition. Items within a list were counterbalanced by using 12 of the 20 rows of a balanced Latin square. Following the presentation of each list there were $20 \mathrm{sec}$ of digit reading and then $2 \mathrm{~min}$ for written free recall.

The intralist activity for each of the five experimental conditions was as follows: Condition 1: Standard free recall-No intralist activity was required; $\mathrm{Ss}$ were instructed to spend their time studying the to-be-remembered items (TBRIs). Condition 2: Repetition-A metronome sounded every second and S was instructed to say the current TBRI twice for each beat of the metronome. Condition 3: Paced low IP task-For each trial $S$ was given a sheet of 80 numbers drawn at random from the set, 1 to 64 . Directly alongside each number was a letter, A or B. The letter A was to be circled if the number was odd, B if the number was even. Instructions to $S$ were that he was to keep pace with the metronome that sounded once per second. On each of the 10 trials $\mathrm{S}$ was given a different list of numbers and the lisis were counterbalanced across Ss. Condition 4: Paced high IP task-Lists identical to those used in Condition 3 were employed, but in this condition $\mathrm{S}$ was instructed to circle the letter $\mathrm{A}$ if the number was high and odd or low and even and to circle B if the number was high and even or low and odd. The pacing was the same as in Condition 3. Condition 5: Unpaced high IP-Instructions and materials for this condition were the same as those for Condition 4 , but $\mathrm{S}$ was told to work as fast as he was able.

RESULTS AND DISCUSSION

Figure 1 shows the serial position curve for the five experimental conditions averaged over all Ss. Since it was clear by examination that there was no significant recency portion (i.e., the digit shadowing task was effective) we performed a Condition by Serial Position analysis of variance over all serial positions. The effect of experimental treatment was significant, $F(4,55)=17.72, p<.001$. An analysis of the pairs of means using Scheffé's method (Hays, 1963, p. 484) shows significant differences beyond the .05 level between each of the three IP tasks and the standard free-recall and repetition conditions. The paced high IP condition is significantly worse in performance than both the low IP condition and the unpaced high IP condition. These latter two conditions do not differ significantly, nor does the

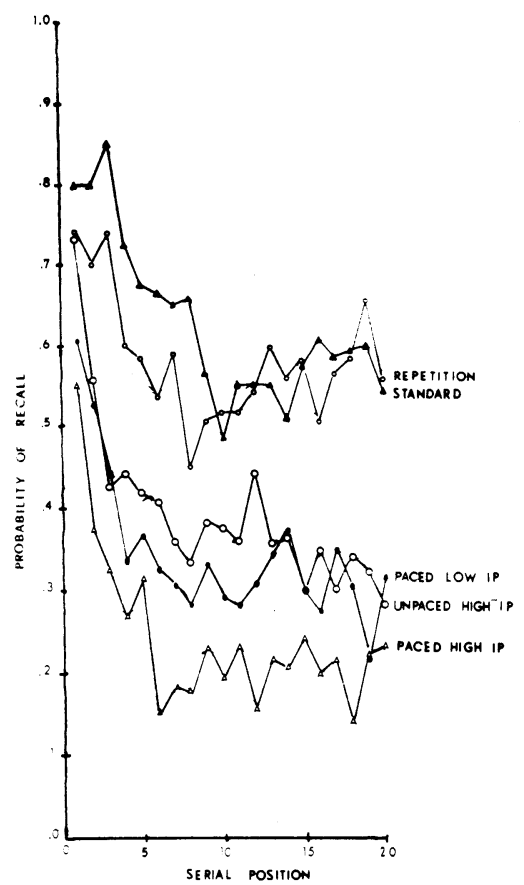

Fig. 1. Serial position curves for five levels of interpolated activity. 
Table 1

Mean Autocorrelation Lag Zero as a Function of Experimental Condition

Condition

\begin{tabular}{lccccc} 
& $\begin{array}{c}\text { Standard } \\
\text { Free Recall }\end{array}$ & Repetition & Low IP & $\begin{array}{c}\text { Unpaced } \\
\text { High IP }\end{array}$ & $\begin{array}{c}\text { Paced } \\
\text { High IP }\end{array}$ \\
\hline Including Primacy & .19 & .10 & .12 & .08 & -.01 \\
Excluding Primacy & .13 & .06 & .05 & .05 & -.06 \\
\hline
\end{tabular}

standard condition differ significantly from the repetition condition. Since examination of the curve in Fig. 1 suggests the possibility that there might be an interaction between the standard condition and repetition condition, a similar analysis of variance was calculated involving only those two conditions. The anticipated interaction effect falls short of statistical significance, $F(19,418)=1.45, p>.05$.

The analysis of variance over the five groups does show a significant effect of serial position, $F(19,1045)=24.20$, $\mathrm{p}<.001$, and a slight interaction (Treatment by Serial Positions), $\mathrm{F}(76,1045)=1.58, \mathrm{p}<.05$. It is conceivable that the interaction is due to the greater relative primacy effect in the IP conditions. However, we should note that the effect is of small magnitude and the scales of measurement are not necessarily linear.

Now that we have described the main results of the study, we shall turn to a comparison of our results to those of Glanzer and Meinzer. Most notable in our data is not our failure to show a statistically significant effect of the repetition condition (as our smaller $\mathrm{N}$ and longer list may account for that difference), but the magnitude of the decrement produced by all the IP tasks as compared to the repetition task. When compared to the standard conditions, the repetition task produces only a $7 \%$ decrement in recall; the unpaced high IP task, paced low IP task, and paced high IP task produced $37 \%, 45 \%$, and $61 \%$ decrements, respectively.

The problem therefore becomes explaining what processes are influenced by the interpolated tasks. Glanzer and Meinzer suggest that effective rehearsal in free recall probably consists of linking individual list words into pairs or longer strings and they argued from their data that rote repetition prevents effective linking. Our results suggest that whatever repetition does, it tends to preserve more

Table

Coefficient of Constraint, D $(\mathrm{N}+1, \mathrm{~N})$, for Experimental Conditions

\begin{tabular}{|c|c|c|c|c|c|}
\hline & \multicolumn{5}{|c|}{ Condition } \\
\hline & $\begin{array}{c}\text { Standard } \\
\text { Free Recall }\end{array}$ & Repetition & Low IP & $\begin{array}{l}\text { Unpaced } \\
\text { High IP }\end{array}$ & $\begin{array}{l}\text { Paced } \\
\text { igh IP }\end{array}$ \\
\hline Including Primacy & .065 & .040 & .050 & .027 & .006 \\
\hline Excluding Primacy & .048 & .029 & .036 & .027 & .002 \\
\hline
\end{tabular}

results. In general, the results for the coefficient, both including and excluding the primacy portion, are quite parallel to these of the autocorrelational analysis.

An examination of overall recall level indicates that the repetition condition produces only a negligible recall decrement while the IP tasks produce an extensive depressive effect. When we turn to the autocorrelations we find the repetition condition about equivalent to all IP tasks excepting paced high IP. These data are suggestive of a two-process explanation of the differences among the groups. Such an explanation would suggest that the standard free-recall and the repetition conditions are alike in allowing a maximum possibility for item recirculation (rehearsal in short-term buffer store, Atkinson \& Shiffrin, 1968) but differ in that the enforced rehearsal reduces the possibility of linking successive items. The repetition condition is like the information-processing conditions in the reduction of intralist hookups but differs in that the IP conditions reduce the possibility of item recirculation. The paced IP test may differ from the paced low IP task in both regards. It is not clear why a difference is obtained between the paced and unpaced high IP conditions. It is not the case that under unpaced conditions $S$ devotes less time to the IP task. Under unpaced conditions Ss process slightly more items. The possibility exists $^{1}$ that not having to pay attention to the clicks serves to facilitate performance in the unpaced condition.

If the explanation of free-recall storage in terms of two processes, item rehearsal and item hookup, is true, the data clearly support the relatively greater importance of item recirculation.

\section{REFERENCES}

ATKINSON, R. C., \& SHIFFRIN, R. M. Human memory: A proposed system and its control processes. In K. W. Spence and J. T. Spence (Eds.), The psychology of learning and motivation. Vol. 2. New York: Academic Press, 1968. Pp. 89-195.

ATTNEAVE, F. Applications of information theory to psychology. New York: Holt, 1959.

GLANZER, M. \& CUNITZ, A. R. Two storage mechanisms in free recall. Journal of Verbal Learning \& Verbal Behavior, 1966, 5, 351-360.

GLANZER, M., \& MEINZER, A. The effects of intra-list activity on free recall. Journal of Verbal Learning \& Verbal Behavior, 1967, 6, 928-935.

GORFEIN, D. S., BENNETT, R. W., ARBAK, C. \& GRAVES, D. Individual differences in the serial position curve of free-recall. Journal of Verbal Learning \& Verbal Behavior, 1969, 8 , 769-772.

HAYS, W. L., Statistics for psychologists. New York: Holt, 1963.

POSTMAN, L., \& PHILLIPS, L. Short-term temporal changes in free recall. Quarterly Journal of Experimental Psychology, 1965, $17,132-138$ 

wordbook of 30,000 words. New York: Bureau of Publications, Teacher's College, Columbia University. 1944.

\section{The influence of texture density gradients on judgments of length*}

\author{
COLIN V. NEWMAN \\ University of Birmingham, Birmingham, England
}

Adult Ss judged the relative lengths of pairs of surfaces viewed successively under restricted monocular conditions. Artificial deformations in the gradients of texture density derived from one surface in each pair had a significant influence on judged length. Surfaces on which the packing density of the texture units progressively increased toward the horizon were judged as longer than surfaces of equal physical dimensions but with evenly spaced texture elements.

In his theory of visual space perception, Gibson (1950, 1959) emphasizes the importance of texture density gradients of stimulation as potential sources of information about depth. Though certain aspects of Gibson's psychophysical hypothesis have been frequently investigated, few experiments have considered the influence of texture variables on judgments of distance within a three-dimensional spatial environment. This short experiment investigates the influence of texture on judgments of the total distance to a single point on a surface, in this case, the visual horizon. Gibson (1959) argues that the specific distance of any single point on a surface is given by the stimulation gradients of disparity and motility at that point, as well as by the degree of density at that point in the textural array relative to the whole gradient of texture density which starts with the image of the nose in the field of view and ends at the visual horizon. The hypothesis to be tested is that variation in the gradients of texture density derived from a surface of constant physical dimensions will influence judgments of its length.

\section{APPARATUS}

Four test surfaces were prepared with different textures. All were $7 \mathrm{ft} 6$ in. $x 2 \mathrm{ft} 6$ in. and were painted crosswise to the line of vision with alternating black and white stripes. On the large regular textured (LRT) and the small

\footnotetext{
* The experiment reported here was one of a series conducted at the University of Leicester, England, where the author held a Social Science Research Council studentship.
}

regular textured (SRT) surfaces, all stripes were equal in width along the length of the surface. Stripes on the LRT surface were $2.0 \mathrm{in}$. wide and on the SRT surface, 1.43 in. wide. There was a progressive increase in the packing density of the stripes which thus progressively became narrower in width from one end of the surface to the other on the slowly decreasing textured (SDT) surface and to a greater extent on the fast decreasing textured (FDT) surface.

Two surfaces at a time were placed horizontally, side by side, on apparatus that permitted Ss to view them lengthwise from one end through a monocular eye-hole in a viewing box. This carried a reduction screen with two apertures. Through these apertures Ss viewed, in turn, the center portion and ends, but not the sides, of both surfaces. Vision beyond the ends of both surfaces was restricted by a white screen, mounted vertically. The FDT and SDT surfaces were placed on the apparatus framework with their wider stripes nearer to the Ss' viewing position.

\section{NOTE}

1. Mr. Steve MacKay of the University of Vichigan suggested this explanation.
The eye-hole was $1 \mathrm{ft}$ above the level of the surfaces. When the FDT and SDT surfaces were viewed at this oblique angle, they provided artificially deformed texture density gradients that corresponded to gradients from longer surfaces with texture elements of equal size throughout. It can thus be predicted that Ss will judge the relative lengths of the surfaces as follows: FDT $>$ SDT $>$ LRT $=$ SRT .

PROCEDURE

Forty-eight adult Ss of both sexes were assigned at random to one of three experimental groups with $16 \mathrm{Ss}$ in each. Each S compared the lengths of only two surfaces before proceeding to a different experiment. Ss in the three experimental groups viewed the following surfaces: Group 1, LRT and FDT; Group 2, SRT and FDT; and Group 3, SRT and SDT.

When each $S$ had been familiarized with the testing procedure, the two apertures in the reduction screen were opened in turn, permitting Ss to view both surfaces successively for $3 \mathrm{sec}$ each. Ss were required to estimate the total length of each surface separately and then report which surface they judged to be physically longer.

\section{RESULTS}

The number of Ss in each experimental group reporting each surface as longer is shown in Table 1.

Responses of "same length" were initially ignored, and the distribution of responses between the two surfaces in each group compared against equal probability using the binomial expansion. Secondly, in the stronger test with the binomial expansion, the responses of "same length" were added to responses of "longer" on the evenly striped surfaces in each group. Results are shown in Table 1.

Informal questioning at the end of the experiment revealed that Ss had not detected any variation in the physical width of the stripes along any surface. After the experiment most Ss expresses surprise when shown that the surfaces were in fact equal in length.

Table 1

Subject's Reports as to Which Surface was Longer

\begin{tabular}{|c|c|c|c|c|c|}
\hline $\begin{array}{l}\text { Experimental } \\
\text { Group }\end{array}$ & Surface & Reported as & Longer & $\begin{array}{c}\text { Binomial } \\
\text { Test } \\
\end{array}$ & $\begin{array}{c}\text { Stronger } \\
\text { Binomial } \\
\text { Test } \\
\end{array}$ \\
\hline 1 & $\begin{array}{c}\text { LRT } \\
1\end{array}$ & $\begin{array}{c}\text { FDT } \\
13\end{array}$ & $\begin{array}{c}\text { Same } \\
2\end{array}$ & $\begin{array}{l}\mathrm{N}=14 \\
x=2 \\
\mathrm{p}<.001\end{array}$ & $\begin{array}{l}N=16 \\
x=3 \\
p<.011\end{array}$ \\
\hline 2 & $\begin{array}{c}\text { SRT } \\
2\end{array}$ & $\begin{array}{c}\text { FDT } \\
12\end{array}$ & $\begin{array}{c}\text { Same } \\
2\end{array}$ & $\begin{array}{l}\mathrm{N}=14 \\
x=2 \\
\mathrm{p}<.006\end{array}$ & $\begin{array}{l}\mathrm{N}=16 \\
x=4 \\
\mathrm{p}<.038\end{array}$ \\
\hline 3 & $\begin{array}{l}\text { SRT } \\
5\end{array}$ & $\begin{array}{c}\text { SDT } \\
11\end{array}$ & $\begin{array}{c}\text { Same } \\
0\end{array}$ & $\begin{array}{l}\mathrm{N}=16 \\
x=5 \\
\mathrm{p}<.105\end{array}$ & $\begin{array}{l}N=16 \\
x=5 \\
p<.105\end{array}$ \\
\hline
\end{tabular}

